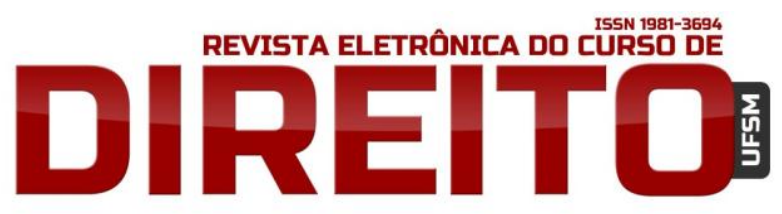

CONTROLE CONSTITUCIONAL DA JORNADA DE TRABALHO: UMA ANÁLISE DOS ACORDÃOS PROFERIDOS PELO TRIBUNAL REGIONAL DO TRABALHO DA QUARTA REGIÃO E PERSPECTIVAS PARA A IMPLEMENTAÇÃO DO E-SOCIAL

\title{
CONTROLE CONSTITUCIONAL DA JORNADA DE TRABALHO: UMA ANÁLISE DOS ACÓRDÃOS PROFERIDOS PELO TRIBUNAL REGIONAL DO TRABALHO DA QUARTA REGIÃO E PERSPECTIVAS PARA A IMPLEMENTAÇÃO DO E-SOCIAL.
}

\author{
CONSTITUTIONAL CONTROL OF WORK SHIFT: AN ANALYSIS OF COURT \\ RULINGS REGIONAL LABOUR THE FOURTH REGION AND PROSPECTS FOR \\ THE IMPLEMENTATION OF E-SOCIAL.
}

\author{
BIBIANE MACHADO DA SILVA \\ Acadêmica do curso de Direito da UFSM atualmente cursando o quarto semestre. \\ Formada em Ciências Contábeis pela mesma instituição. \\ bibiane.contadora@yahoo.com.br
}

\section{RESUMO}

Dentre os direitos trabalhistas e previdenciários, o presente trabalho restringe-se ao preceito balizado pelo artigo $7^{\circ}$ inciso XIII da Constituição Federal. Tal dispositivo faz referência à limitação da jornada de trabalho. Dessa forma, este estudo objetiva realizar uma análise das decisões colegiadas proferidas pelo TRT da $4^{\text {a }}$ Região nos três últimos trimestres de 2013 e nos três primeiros trimestres de 2014. Para tanto serão apreciados os acórdãos ocorridos nesse período com a finalidade de verificar se houve aumento ou diminuição de demandas envolvendo o ponto eletrônico. Além disso, o estudo busca projetar tendências após a implantação da plataforma E-Social. Assim, há a necessidade de mais políticas elucidativas concernentes ao tempo de labor dos trabalhadores, bem como mudança cultural de muitos empresários que submetem seus empregados a jornadas exaustivas.

Palavras-chave: direitos trabalhistas e previdenciários; e-social; jornada de trabalho; ponto eletrônico.

\begin{abstract}
Among the labor and social security rights, the present work is restricted to the precept buoyed by Article 7 paragraph XIII of the Constitution. Such a device refers to the limitation of the working day. Thus, this study aims to conduct an analysis of collective decisions made by TRT's 4th District in the last three quarters of 2013 and the first three quarters of 2014. For both the judgments will be appreciated that occurred during this period in order to ascertain whether there was an increase or decrease in claims involving electronic point. In addition, the study seeks to project trends after the implementation of E-Social platform. Thus, there is a need for more political instructive concerning the labor time of workers, as well as cultural change that many entrepreneurs submit their employees to exhausting journeys.
\end{abstract}

Keywords: electronic point; e-social; labor and social security rights; workday.

\section{SUMÁRIO}

INTRODUÇAO; 1 JORNADA DE TRABALHO; 1.1 Conceituação; 1.2 Do controle da jornada de trabalho legislação relacionada; 1.3 Do ponto eletrônico; 1.4 Do E-Social; 2 ANÁLISE DAS DECISÕES COLEGIADAS EMANADAS PELO TRIBUNAL REGIONAL DO TRABALHO DA QUARTA REGIÃO; 2.1 Do quantitativo de acórdãos relacionados ao ponto eletrônico; 2.2 Análise das informações; 2.3 Projeção para o E-Social; CONCLUSÃO; REFERÊNCIAS. 


\section{INTRODUÇÃO}

Atualmente, o controle da jornada de trabalho em muitas empresas não tem sido realizado de forma eficaz. Embora, a Portaria 1.510 de 2009 do Ministério do Trabalho e Emprego (MTE) tenha sido responsável por efetivar a adesão do ponto eletrônico para facilitar o controle em empresas com mais de 10 (dez) funcionários, é notório que muitos trabalhadores ainda são submetidos a jornadas superiores ao permitido em nossa Carta Magna.

Dessa forma, levantam-se os seguintes questionamentos: Em que medida o sistema atual de controle da jornada, em empresas que optaram pelo registro do ponto eletrônico, está influenciando no número de demandas apreciadas em nível recursal pelo TRT da $4^{\text {a }}$ Região no ano de 2014? E o novo sistema de escrituração digital das obrigações trabalhistas e previdenciárias, o E-Social, previsto para ser implementado em 2015 conseguirá juntamente com ponto eletrônico (ou o substituindo) atingir o objetivo de submeter os empregadores abrangidos pelo TRT 4 ao parâmetro de duração do trabalho de seus empregados, aduzido no artigo $7^{\circ}$ inciso XIII da Constituição Federal Brasileira?

O objetivo geral do presente estudo é analisar se a opção pelo ponto eletrônico impactou no sistema de controle de jornada dos trabalhadores, pelo menos no âmbito de jurisdição do mesmo tribunal, bem como projetar uma possibilidade do que poderá vir a ocorrer após a implantação da plataforma do E-Social.

Já os objetivos específicos são: verificar, através da coleta de dados junto ao Portal do TRT 4 se houve diminuição, aumento ou se permaneceu inalterado o número de demandas envolvendo controle das jornadas de trabalho via ponto eletrônico nos três últimos trimestres de 2013 e nos três primeiros trimestres de 2014. Discutir, com base nesses dados, se a plataforma do E-Social quando for obrigatória para o mesmo grupo de empresas, será capaz de frear o problema das jornadas superiores ao permitido, também no âmbito jurisdicional do aludido Tribunal.

Neste trabalho será utilizado o método de abordagem dedutivo. Esta metodologia pode partir de dados estatísticos para construir hipóteses e inferir conclusões mais amplas.

Segundo Marconi e Lakatos ${ }^{1}$ "os argumentos dedutivos sacrificam a ampliação do conteúdo para atingir a certeza".

${ }^{1}$ MARCONI, M. A., LAKATOS, E. M. Fundamentos de Metodologia Científica. 6 ed. São Paulo: Atlas, 2005 p. 92 
0 procedimento adotado será o método descritivo. Para tanto, será realizada uma pesquisa junto ao Portal do TRT 4 relacionando o quantitativo de demandas analisadas em grau de recurso pelas turmas envolvendo jornadas de trabalho superiores ao permitido na Constituição Federal posteriores à Portaria 1.510 de 2009 do MTE.

Esses dados serão compilados em períodos trimestrais. Os dados serão restritos aos empregadores que optaram pelo registro da jornada de trabalho via ponto eletrônico, mas que, segundo as partes autoras, vêm desrespeitando a limitação constitucional.

Logo após a obtenção desses dados, os mesmos serão tratados e formarão hipóteses que darão a base para análise da (in)efetividade da legislação que adotou o ponto eletrônico. Além disso, os dados também poderão auxiliar na projeção de como os empregadores irão se comportar após a obrigatoriedade relativa ao E - Social. 0 artigo abordará os conceitos de: jornada de trabalho e seu controle, ponto eletrônico e E-Social. Em seguida irá analisar os dados obtidos junto ao Portal do TRT da $4^{\text {a }}$ Região relativos às lides de sobrejornada envolvendo o ponto eletrônico e para finalizar uma abordagem da expectativa para a implementação do ESocial.

\section{JORNADA DE TRABALHO}

\subsection{Conceituação}

A partir da Revolução Industrial, os seres humanos foram segregados, segundo Karl Marx em duas classes: os detentores e os não detentores dos meios de produção. Estes, desde então, para sobreviver vendem sua força de trabalho em troca de um salário para aqueles, os quais se apropriam do excedente denominado de mais-valia. Tal momento histórico foi marcado por submissão a jornadas extremamente degradantes, inclusive para mulheres e crianças.

A relação econômica passou do capitalismo puro e simples para o Liberalismo. Atualmente a sociedade vive na era globalizada do Neoliberalismo. E, durante todas essas etapas os direitos dos trabalhadores também foram sendo modificados a nível mundial. Em certa medida, neste ponto se evoluiu consideravelmente em termos normativos.

O rol de direitos trabalhistas é muito vasto, contudo neste trabalho será tratado do direito adquirido relativo à jornada de trabalho.

A finalidade do Direito do Trabalho consiste na: 
...proteção jurídica ao trabalhador, necessária, de uma parte, porque a relação de emprego, implicando na prestação de serviços sob as ordens e a direção do empregador, e em organização e ambiente por este predispostos, que podem acarretar riscos para a incolumidade física e moral do empregado, compromete a própria pessoa deste, de que é inseparável a energia de trabalho. ${ }^{2}$

Inicialmente, faz-se necessário conceituar o termo jornada de trabalho: “é a quantidade de labor diário do empregado"3.

A natureza jurídica do trabalho é "de natureza mista”, pois coexistem "elementos com características pública e privada"4.

A jornada laboral interfere em grande medida na vida do trabalhador, pois uma parte considerável do seu dia é destinada ao labor. Nesse contexto, José Luis Bolzan de Morais ${ }^{5}$ demonstra que:

A introjeção de uma "coerção interna" para o trabalhador regular parece ser imprescindível para a consecução dos resultados de adaptação do trabalhador tradicional às novas relações de produção, onde ele perde o controle sobre sua vida diária.

O empregado, porém, não se submete a jornadas exaustivas apenas por medo de seu empregador, mas principalmente por necessidade. Neste ponto, brilhantemente Luiz de Pinho Pedreira da Silva ${ }^{6}$ demonstra que:

Quem precisa do emprego para sobreviver com o salário que ele propicia, seu único ou principal meio de subsistência, tendo a sua atividade absorvida total ou predominantemente pelo empregador, detentor dos meios de produção, que ele trabalhador não possui.

Assim, pode-se inferir dessa afirmação que a sujeição do trabalhador decorre, em grande medida, da emergência em prover o sustento de sua família. Isso acaba, por vezes, anulando sua capacidade reflexiva com relação à exploração que sofre.

\footnotetext{
${ }^{2}$ SILVA, LUIZ DE PINHO PEDREIRA DA, Principiologia do Direito do Trabalho, 2 ed. São Paulo: LTR, 1999. p. 124

${ }^{3}$ MARTINS, SERGIO PINTO, Direito do Trabalho, 29 ed. São Paulo: Atlas, 2013. p. 550

${ }^{4}$ MARTINS, SERGIO PINTO, Direito do Trabalho, 29 ed. São Paulo: Atlas, 2013. p. 551

${ }^{5}$ MORAIS, JOSÉ LUIS BOLZAN DE, A subjetividade do tempo, 1 ed. Porto Alegre: Livraria do Advogado, 1998. p. 40

${ }^{6}$ SILVA, LUIZ DE PINHO PEDREIRA DA, Principiologia do Direito do Trabalho, 2 ed. São Paulo: LTR, 1999. pg 25
} 
CONTROLE CONSTITUCIONAL DA JORNADA DE TRABALHO: UMA ANÁLISE DOS ACÓRDÃOS PROFERIDOS PELO TRIBUNAL REGIONAL DO TRABALHO DA QUARTA REGIÃO E PERSPECTIVAS PARA A IMPLEMENTAÇÃO DO E-SOCIAL

\subsection{Do controle da jornada de trabalho - legislação relacionada}

Sob a inteligência de nossa Carta Magna, a limitação da jornada laboral dos trabalhadores brasileiros está ancorada no artigo $7^{\circ}$, inciso $\mathrm{XIII}^{7}$ :

Art. $7^{\circ}$ São direitos dos trabalhadores urbanos e rurais, além de outros que visem à melhoria de sua condição social:

...XIII - duração do trabalho normal não superior a oito horas diárias e quarenta e quatro semanais, facultada a compensação de horários e a redução da jornada, mediante acordo ou convenção coletiva de trabalho;

A limitação constitucional, portanto, justifica-se pelos seguintes fundamentos: biológicos, sociais, econômicos e humanos ${ }^{8}$.

Biológicos no sentido de combater a fadiga, os sociais no que tange ao convívio no seio familiar e da comunidade a qual faz parte, econômicos no sentido de maior geração de emprego e renda e finalmente humanos para se evitar acidentes de trabalho.

Por óbvio, o legislador ao conceber a limitação da jornada abarcou exceções, algumas delas constam no artigo 61 da Consolidação das leis Trabalhistas (CLT):

Art. 61 - Ocorrendo necessidade imperiosa, poderá a duração do trabalho exceder do limite legal ou convencionado, seja para fazer face a motivo de força maior, seja para atender à realização ou conclusão de serviços inadiáveis ou cuja inexecução possa acarretar prejuízo manifesto.

$\S 1^{\circ}$ - 0 excesso, nos casos deste artigo, poderá ser exigido independentemente de acordo ou contrato coletivo e deverá ser comunicado, dentro de 10 (dez) dias, à autoridade competente em matéria de trabalho, ou, antes desse prazo, justificado no momento da fiscalização sem prejuízo dessa comunicação.

$\S 2^{\circ}$ - Nos casos de excesso de horário por motivo de força maior, a remuneração da hora excedente não será inferior à da hora normal. Nos demais casos de excesso previstos neste artigo, a remuneração será, pelo menos, $25 \%$ (vinte e cinco por cento) superior à da hora normal, e o trabalho não poderá exceder de 12 (doze) horas, desde que a lei não fixe expressamente outro limite.

$\S 3^{\circ}$ - Sempre que ocorrer interrupção do trabalho, resultante de causas acidentais, ou de força maior, que determinem a impossibilidade de sua realização, a duração do trabalho poderá ser prorrogada pelo tempo necessário até o máximo de 2 (duas) horas, durante o número de dias indispensáveis à recuperação do tempo perdido, desde que não exceda de 10 (dez) horas diárias, em período não superior a 45 (quarenta e cinco) dias por ano, sujeita essa recuperação à prévia autorização da autoridade competente.

${ }^{7}$ BRASIL. Constituição Federal. Brasília: Senado Federal, 1988.

${ }^{8}$ MARTINS, SERGIO PINTO, Direito do Trabalho, 29 ed. São Paulo: Atlas, 2013, p.552. 
CONTROLE CONSTITUCIONAL DA JORNADA DE TRABALHO: UMA ANÁLISE DOS ACÓRDÃOS PROFERIDOS PELO TRIBUNAL REGIONAL DO TRABALHO DA QUARTA REGIÃO E PERSPECTIVAS PARA A IMPLEMENTAÇÃO DO E-SOCIAL

É importante salientar que a prorrogação permitida no ordenamento decorre de fato atípico e esporádico ou em determinadas profissões. Mais uma vez o legislador optou pela proteção generalista da integridade dos trabalhadores. Visto que:

A nulidade de renúncia pelo trabalhador de seus direitos encontra fundamento legal em nosso ordenamento, pois o artigo $9^{\circ}$ da CLT declara nulos os atos praticados com o objetivo de desvirtuar, impedir ou fraudar a aplicação dos preceitos nela contidos'.

Entretanto, muitos empregadores quando demandados ainda invocam o artigo 61 (CLT) para justificar o excesso de jornada de seus empregados. Essa estratégia, na maioria das vezes, torna-se infrutífera visto que muitos desses empregadores não conseguem promover a necessária carga probatória.

Neste sentido, para coibir tal prática o legislador elaborou a Lei 10803 de $2003^{10}$ a qual modifica o artigo 149 do Código Penal ${ }^{11}$ :

\footnotetext{
Art. 149-Reduzir alguém a condição análoga à de escravo, quer submetendo-o a trabalhos forçados ou a jornada exaustiva (grifo nosso), quer sujeitando-o a condições degradantes de trabalho, quer restringindo, por qualquer meio, sua locomoção em razão de dívida contraída com o empregador ou preposto:

Pena - reclusão, de dois a oito anos, e multa, além da pena correspondente à violência.

$\S 1^{\circ}$ Nas mesmas penas incorre quem:

$\mathrm{I}$ - cerceia o uso de qualquer meio de transporte por parte do trabalhador, com o fim de retê-lo no local de trabalho;

II - mantém vigilância ostensiva no local de trabalho ou se apodera de documentos ou objetos pessoais do trabalhador, com o fim de retê-lo no local de trabalho.

$\S 2^{\circ}$ A pena é aumentada de metade, se o crime é cometido:

I - contra criança ou adolescente;

II - por motivo de preconceito de raça, cor, etnia, religião ou origem."
}

Pode-se deduzir deste dispositivo que a prática é tão comum, que o legislador percebeu a necessidade de sanção ao empregador na esfera penal, na tentativa de coibir tal conduta.

Assim, "a idéia do marchandage, da exploração do homem pelo próprio homem, não pode existir”12. Essa expressão nada mais é do que locação de mão-de-obra, intermediada por uma empresa "terceirizada", o que, entretanto, é repudiada pela legislação trabalhista, uma vez que

${ }^{9}$ SILVA, LUIZ DE PINHO PEDREIRA DA, Principiologia do Direito do Trabalho, 2 ed. São Paulo: LTR, 1999. p. 128

${ }^{10}$ MARTINS, SERGIO PINTO, Direitos Fundamentais Trabalhistas, 1 ed. São Paulo: Atlas, 2008.

${ }^{11}$ LEI 10.803 DE 11 DE DEZEMBRO DE 2003

${ }^{12}$ MARTINS, SERGIO PINTO, Direitos Fundamentais Trabalhistas, 1 ed. São Paulo: Atlas, 2008.(p. 85) 
o contrato de locação possui como objeto "coisas" passíveis de serem submetidas ao aluguel. Essa analogia, portanto, reduz o homem e sua dignidade à “coisificação".

\subsection{Do ponto eletrônico}

Outrossim, o legislador novamente vem ao encontro dos anseios dos trabalhadores, quando, em 2009 publica a Portaria 1510 do Ministério do Trabalho e emprego (MTE). Esta normativa possui como cerne a preocupação do Gestor Público em submeter os empregadores a um efetivo controle da jornada de seus colaboradores. Para isso, na inteligência do Artigo 74 da CLT é definido que:

Art. 74 - O horário do trabalho constará de quadro, organizado conforme modelo expedido pelo Ministro do Trabalho, Indústria e Comercio, e afixado em lugar bem visível. Esse quadro será discriminativo no caso de não ser o horário único para todos os empregados de uma mesma seção ou turma.

...§ $2^{\circ}$ - Para os estabelecimentos de mais de dez trabalhadores será obrigatória a anotação da hora de entrada e de saída, em registro manual, mecânico ou eletrônico (grifo nosso), conforme instruções a serem expedidas pelo Ministério do Trabalho, devendo haver pré-assinalação do período de repouso.

$\S 3^{\circ}$ - Se o trabalho for executado fora do estabelecimento, o horário dos empregados constará, explicitamente, de ficha ou papeleta em seu poder, sem prejuízo do que dispõe o $§ 1^{\circ}$ deste artigo.

Neste trabalho, contudo, como já dito, foi eleito especificadamente o ponto eletrônico para o referido controle.

O texto da Portaria $1510^{13}$ deixa claro que:

Art. $2^{\circ} O$ SREP (Sistema de Registro Eletrônico de Ponto) deve registrar fielmente as marcações efetuadas, não sendo permitida qualquer ação que desvirtue os fins legais a que se destina, tais como: (grifo nosso)

I - restrições de horário à marcação do ponto;

II- marcação automática do ponto, utilizando-se horários predeterminados ou o horário contratual;

III - exigência, por parte do sistema, de autorização prévia para marcação de sobrejornada; e

IV - existência de qualquer dispositivo que permita a alteração dos dados registrados pelo empregado.

\footnotetext{
${ }^{13}$ PORTARIA No 1.510 , DE 21 DE AGOSTO DE 2009
} 
Agregado a isso, a intenção do sistema parece buscar a lisura do processo de controle da jornada, visto que:

Art. 11. Comprovante de Registro de Ponto do Trabalhador é um documento impresso para o empregado acompanhar, a cada marcação, o controle de sua jornada de trabalho, contendo as seguintes informações:

I - cabeçalho contendo o título "Comprovante de Registro de Ponto do Trabalhador";

II - identificação do empregador contendo nome, CNPJ/CPF e CEI, caso exista;

III - local da prestação do serviço;

IV - número de fabricação do REP;

$\mathrm{V}$ - identificação do trabalhador contendo nome e número do PIS;

$\mathrm{VI}$ - data e horário do respectivo registro; e

VII - NSR (Número Sequencial de Registro).

...ङ $2^{\circ} 0$ empregador deverá disponibilizar meios para a emissão obrigatória do Comprovante de Registro de Ponto do Trabalhador no momento de qualquer marcação de ponto.

Entretanto, embora exista o documento de comprovação do trabalhador, isso não garante a inexistência de excesso na carga horária, uma vez que é de conhecimento de todos que alguns empregadores obrigam seus funcionários a "bater o ponto" e a retornar ao trabalho se submetendo a jornadas de 12 (doze), 14(quatorze) horas (realidade não muito diferente da atacada por Marx em meados do século XVIII):“... graças `a elevação da intensidade do trabalho e ao prolongamento forçado da jornada de trabalho, a mais valia aumentou, então, absoluta e relativamente" 14 .

Tanto o é que, a conduta errônea dos empregadores é expressamente vedada pela Portaria 1510 em seu artigo $2^{\circ}$ já citado.

Com a pesquisa pretende-se verificar a efetividade (ou não) do ponto eletrônico, como política governamental no sentido amplo com relação ao controle de jornada anterior à sua adesão por parte dos empregadores com mais de dez funcionários. Cientes de que há desrespeito, como a muitas normas brasileiras, mas na esperança de que este sistema possa ter minimizado o problema.

\subsection{Do E-Social} ${ }^{14}$ MARX, KARL, O Capital: crítica da economia política- livro 1, 15 ed. Rio de Janeiro: Berthand Brasil,
1996. p.605 
Recentemente, o governo vem trabalhando para conceber a nova metodologia de controle e envio das informações trabalhistas e previdenciárias: o E-Social ${ }^{15}$.

O E-Social é um projeto do governo federal que vai coletar as informações descritas no Objeto do E-Social, armazenando-as no Ambiente Nacional do ESocial, possibilitando aos órgãos participantes do projeto, sua efetiva utilização para fins previdenciários, fiscais e de apuração de tributos e do FGTS.

Essa plataforma, a qual está em fase final de implementação "na prática a obrigatoriedade não virá antes da metade de 2015" e "primeiro só para as grandes empresas" e ainda "o cronograma para as demais empresas ainda está em discussão."16

Seu objeto é visualizado no manual ${ }^{17}$ :

O e-Social tem por objeto estabelecer a forma única com que passam a ser prestadas as informações trabalhistas, previdenciárias, tributárias e fiscais relativas à contratação e utilização de mão de obra onerosa, com ou sem vínculo empregatício e também de outras informações previdenciárias previstas na lei $\mathrm{n}^{\circ}$ 8.212, de 24 de julho de 1991, e de rendimentos pagos por si sujeitos à retenção na fonte.

O projeto de implementação do E-Social, portanto, virá ao encontro das demandas de todos os órgãos fiscalizadores da Gestão de Mão de Obra do país, pois até então existe grande dificuldade de fiscalização devido ao fato de que as informações são geradas e tratadas em sistemas diversos (SEFIP- Sistema Empresa de Recolhimento do FGTS, CAGED- Cadastro Geral de Empregados e Desempregados, RAIS- Relação Anual de Informações Sociais) o que prejudica em grande medida o controle pelo gestor público.

Já no que tange ao controle da jornada de trabalho no E-Social, não foi encontrado nenhuma menção específica de mudança no controle da jornada no manual atualmente disponível em seu sítio na internet, o que se leva a crer, em princípio, que serão mantidas as formas de controle já implementadas. Dentre elas o ponto eletrônico.

\footnotetext{
${ }^{15}$ Manual de Orientação do E-Social , p. 8

16 Noticia vinculada em O ESTADO DE SÃO PAULO em 22/05/2014.

17 Manual de Orientação do E-Social , p. 8
} 


\section{(1) DIREITOT}

CONTROLE CONSTITUCIONAL DA JORNADA DE TRABALHO: UMA ANÁLISE DOS ACÓRDÃOS PROFERIDOS PELO TRIBUNAL REGIONAL DO TRABALHO DA QUARTA REGIÃO E PERSPECTIVAS PARA A IMPLEMENTAÇÃO DO E-SOCIAL

\section{ANÁLISE DAS DECISÕES COLEGIADAS EMANADAS PELO TRIBUNAL REGIONAL DO TRABALHO DA QUARTA REGIÃO}

\subsection{Do quantitativo de acórdãos relacionados ao ponto eletrônico}

A coleta de dados foi realizada no sistema de consultas do Portal: <http://www.trt4.jus.br/>. Os parâmetros de busca foram as palavras: ponto eletrônico; cartões ponto; registro eletrônico de ponto; Tipo - Acórdãos; Classes- todas as classes; Redatores - todos os redatores. Foram realizadas seis pesquisas: a primeira relativa ao segundo trimestre de 2013 (01/04/2013 a 30/06/2013), a segunda relativa ao terceiro trimestre de 2013 $(01 / 07 / 2013$ a 30/09/2013), a terceira relativa ao quarto trimestre de $2013(01 / 10 / 2013$ a 31/12/2013), a quarta relativa ao primeiro trimestre de $2014(01 / 01 / 2014$ a 31/03/2014), a quinta relativamente ao segundo trimestre de 2014 (01/04/2014 a 30/06/2014) e a sexta relativa ao terceiro trimestre de 2014 (01/07/2014 a 30/09/2014).

A escolha desses parâmetros decorre da necessidade de se verificar a procedência de tais demandas trazidas geralmente pelos (ex) empregados, uma vez que, supõe-se no grau de recurso, houve em primeiro grau uma sentença no mínimo parcialmente procedente em favor do hipossuficiente. Certamente, há exceções quanto a este raciocínio, mas que não serão possíveis de se analisar neste trabalho.

$\mathrm{Na}$ primeira pesquisa retornou 537 (quinhentos e trinta e sete) resultados correspondentes ao período de 01/04/2013 a 30/06/2013. A segunda pesquisa retornou 602 (seiscentos e dois) resultados correspondentes ao período de 01/07/2013 a 30/09/2013. Na terceira pesquisa retornou 667 (seiscentos e sessenta e sete) resultados correspondentes ao período de 01/10/2013 a 31/12/2013. Na quarta pesquisa retornou 353 (trezentos e cinquenta e três) resultados correspondentes ao período de 01/01/2014 a 31/03/2014. Na quinta pesquisa retornou 765 (setecentos e sessenta e cinco) resultados correspondentes ao período de 01/04/2014 a 30/06/2014. E, na sexta e última pesquisa retornou 772 (setecentos e setenta e dois) resultados correspondentes ao período de 01/07/2014 a 30/09/2014.

\subsection{Análise das informações}



ANÁLISE DOS ACÓRDÃOS PROFERIDOS PELO TRIBUNAL REGIONAL DO TRABALHO DA QUARTA REGIÃO E PERSPECTIVAS PARA A IMPLEMENTAÇÃO DO E-SOCIAL

Certamente, analisar apenas o período correspondente a cinco semestres e afirmar categoricamente que a Portaria 1.510 de 2009 do MTE está sendo ineficaz seria prepotência demasiada desta que vos escreve.

Contudo, há de se analisar o aumento no número de demandas que passaram de 537 no antepenúltimo trimestre de 2013 (01/04/2013 a 30/06/2013) para 772 no terceiro trimestre de 2014 (01/07/2014 a 30/09/2014). Mesmo com as ocorrências de Copa do Mundo no Brasil e das férias forenses, há de observar a considerável elevação.

O evento desportivo ocorreu de 12/06/2014 a 13/07/2014 possuindo como uma das sedes a capital Porto Alegre -RS, também sede do Tribunal Regional do Trabalho da Quarta Região. No respectivo período os horários foram reduzidos por determinação da Portaria 1.423 (dias 18/06, 25/06 e 30/06 das 08:00 as 12:00 e dias 12/06, 17/06 e 23/06 das 08:00 as 14:00).

Já o período de férias forenses, digo feriado forense, segundo o artigo 62 da Lei 5.010 de 1966, ocorre anualmente de 20 de dezembro a 06 de janeiro. Estes dois momentos provavelmente prejudicaram o número de julgamentos nos referidos períodos.

Todavia, o crescimento é visível e pode demonstrar que: a conduta reiterada de desrespeito ao limite constitucional não está sendo devidamente reprimida pelo Ministério do Trabalho e Emprego e muitos empregadores acreditam estar no direito de compensar a carga tributária explorando seus funcionários.

O Ministério do Trabalho e Emprego é o órgão responsável por fiscalizar as condições laborativas dos trabalhadores, além de verificar se INSS, FGTS e outras contribuições estão sendo recolhidas regularmente. Entretanto, devido ao notório déficit com relação ao número de auditores, acaba restringindo o trabalho de fiscalização as amostragens e denúncias recebidas. Essa realidade infelizmente permite que muitos empregadores continuem explorando seus empregados, pois estes, muitas vezes desconhecem seus direitos ou tem medo de denunciar no curso de seus contratos.

O segundo ponto supra-citado, decorre da cultura nacional de “levar vantagem em tudo". Neste sentido, cita-se novamente Marx quando este reflete sobre a exploração dos detentores dos meios de produção (Teoria ainda bem atual):

A produção da mais valia absoluta se realiza com o prolongamento da jornada de trabalho além do ponto em que o trabalhador produz apenas um equivalente ao valor de sua força de trabalho e com a apropriação pelo capital desse excedente. 
CONTROLE CONSTITUCIONAL DA JORNADA DE TRABALHO: UMA ANÁLISE DOS ACÓRDÃOS PROFERIDOS PELO TRIBUNAL REGIONAL DO TRABALHO DA QUARTA REGIÃO E PERSPECTIVAS PARA A IMPLEMENTAÇÃO DO E-SOCIAL

Ela constitui o fundamento do sistema capitalista e o ponto de partida da produção da mais valia relativa. ${ }^{18}$

Ocorre que muitos empresários, reclamam demasiadamente da "Carga Tributária Brasileira", inclusive sobre a folha de pagamento, com certa razão, todavia, este argumento não pode ser utilizado como justificativa para compensar os gastos com tributos explorando seus colaboradores. Principalmente após a política de desoneração da folha de pagamento instituída pela atual gestão do governo federal.

Com o intuito de tentar clarificar a análise deste estudo, será transcrito parcialmente o voto do desembargador LUIZ ALBERTO DE VARGAS (relator do Acórdão 000178673.2012.5.04.0341 RO - 10 a turma TRT 4 proferido em 10/04/2014):

\begin{abstract}
...A esse respeito, comentando as possibilidades de fraude dos sistemas informatizados de ponto, em estudo realizado com o Engenheiro Carlos Augusto Moreira dos Santos, Professor e Mestre em Informática, tivemos ocasião de dizer que: "A forma mais comum de fraude da jornada de trabalho tem sido a do registro falso. $\mathrm{O}$ empregado (ou um preposto do empregador como se fosse este) "bate o ponto" em horário distinto daquele em que efetivamente ocorreu a chegada ou saída da empresa. Este tipo de fraude tem sido combatido por fiscalizações surpresa dos fiscais do trabalho, por prova testemunhal em processos judiciais ou pela prova documental (muitas vezes por meio de relatórios informatizados de atividades do empregado que demonstram que este trabalhava normalmente em horário em que, pelo registro ponto, não estava no estabelecimento). Diga-se, a bem da verdade, que tal tipo de fraude em nada se altera pela adoção dos meios informatizados de controle. Um outro tipo de fraude, porém, muito mais danoso e potencialmente mais difícil de constatar, pode ser praticado por meios dos programas de ponto eletrônico. Trata-se da possibilidade de alteração, a posteriori, dos próprios registros de entrada e saída, por meio de operações de "correção" feitas pelo empregador ou seus prepostos. Em geral, justificam as empresas a existência de tais "portas dos fundos" no programa por uma suposta conveniência de corrigir registros realizados por equívoco pelo empregado.Tais procedimentos "corretivos" não deixam rastro, nem as alterações ocorridas são detectáveis pelo empregado ou por outro que não seja o próprio fraudador. 0 empregado sequer fica sabendo que os registros que consignou foram adulterados posteriormente. Nos relatórios, igualmente, não é necessário que constem as alterações, criando-se um documento de conteúdo absolutamente falso, mas com aparência de autêntico. É inevitável - e alarmante, dada a semelhança entre fato e ficção - correlacionar tal prática às "retificações" dos registros históricos feitas pelo Departamento de Registro no 1984 de Orwell. Os riscos de fraude não se limitam às adulterações de registros de entrada e saída. Estendem-se ao próprio tratamento dos dados. Assim, por
\end{abstract}

\footnotetext{
${ }^{18}$ MARX, KARL, O Capital: crítica da economia política- livro 1, 15 ed. Rio de Janeiro: Berthand Brasil, 1996. p.585
} 
CONTROLE CONSTITUCIONAL DA JORNADA DE TRABALHO: UMA ANÁLISE DOS ACÓRDÃOS PROFERIDOS PELO TRIBUNAL REGIONAL DO TRABALHO DA QUARTA REGIÃO E PERSPECTIVAS PARA A IMPLEMENTAÇÃO DO E-SOCIAL

exemplo, o programa pode fazer com que as compensações de horas extras sejam feitas na base de uma hora de folga a cada duas horas trabalhadas, sem que tal procedimento fique explícito em qualquer relatório. Mais uma vez, aqui, o sistema informatizado serve como uma cortina de perfeição que pode ser usada para fraudar direitos do empregado. Outro caso de fraude no tratamento de dados pode ser apontado na apropriação dos horários. Por exemplo, o critério adotado no programa poderia ser o de somente considerar jornada extraordinária aquela trabalhada após quinze minutos além do horário normal. Teríamos mais uma fraude a ocasionar prejuízos consideráveis ao empregado, sendo que tanto este como a fiscalização trabalhista teria enormes dificuldades de identificar tal critério velado, que ficaria escondido dentro da programação original ou poderia ser ativado eventualmente pelo empregador. A única maneira de constatar critérios ocultos seria a análise, por perito altamente especializado em programação, do código fonte do programa - algo que, sem dúvida, não conta com a simpatia dos fabricantes de software, pelas já referidas razões de proteção à propriedade intelectual. E mesmo a simples análise do código-fonte seria insuficiente, pois nada impede que o programa efetivamente instalado no computador da empresa tenha sofrido modificações específicas, não constantes no código-fonte submetido à perícia. Assim, não bastaria a análise do códigofonte, mas seria preciso também um teste de consistência para determinar se determinado programa foi ou não alterado concretamente em relação a seu original. Em teoria isto é possível, mas na prática é muito difícil de se fazer. A situação atual implica em um substancial desequilíbrio nas relações trabalhistas. 0 empregador tem poder quase absoluto sobre as informações relativas à prestação do trabalho, ao passo que o empregado não tem garantia de que os registros de entrada e saída (feitos por ele mesmo) estão a salvo de fraude. Urge que se estabeleçam regras mais claras para o uso do ponto eletrônico, que permitam estabelecer maior equilíbrio na relação. Sem isto, os abusos são quase impossíveis de evitar e muito difíceis de punir. (Luiz Alberto de Vargas e Carlos Augusto Moreira dos Santos, "O software de Controle de Jornada de Trabalho é Seguro e Confiável?", maio/2002, publicado na Suplemento LTr , 086/02, p. 37988 e na Revista de Jurisprudência Trabalhista HS, n. 222, junho/2002)."

A referida transcrição demonstra que as fraudes ao REP (Registro Eletrônico de Ponto) podem ser mais sofisticadas e imperceptíveis das que foram inicialmente levantadas no estudo. $E$, vão bem além da simples submissão do trabalhador a efetuar o registro de jornada e retornar ao posto de trabalho. Então como combatê-las?

Uma alternativa a ser debatida poderia ser a elaboração de um sistema unificado para o REP disponibilizado pelo MTE e com manipulação dos códigos fontes apenas por este órgão como já ocorre, por exemplo, com a Conectividade Social (aplicativo da Caixa Econômica Federal responsável pelo recolhimento do FGTS (Fundo de Garantia por Tempo de Serviço) dos empregados.

Nesse sistema, existem duas formas de transmissão das referidas informações: a primeira destina-se aos empregadores dispensados da obrigatoriedade de Certificação Digital. Neste caso, o mesmo faz o download do Sistema via Portal da Caixa Econômica Federal, alimenta-o com as 
informações e só as transmite sem ter acesso algum aos códigos-fonte, nem mesmo possibilidade de modificação do layout. Já para os empregadores obrigados a Certificação Digital, o aplicativo é totalmente online, o que também impede alterações no layout e códigos-fonte.

O modelo aplicado a Conectividade Social, portanto, parece ser mais efetivo, podendo assim servir de paradigma no confronto as fraudes digitais ao REP.

\title{
2.3 Projeção para o E-Social
}

Conforme já citado na parte teórica relativa ao E-Social, ainda há indefinição quanto à permanência ou não do REP (Registro Eletrônico de Ponto) após a implementação do novo sistema para o controle da jornada de trabalho. O que se sabe é que os elaboradores do E-Social estão projetando uma plataforma capaz de harmonizar:

\begin{abstract}
Atendimento a diversos órgãos do governo com uma única fonte de informações, para o cumprimento das diversas obrigações trabalhistas, previdenciárias e tributárias atualmente existentes;

Integração dos sistemas informatizados das empresas com o ambiente nacional do eSocial, possibilitando a automação na transmissão das informações dos empregadores;

Padronização e integração dos cadastros das pessoas físicas e jurídicas no âmbito dos órgãos participantes do projeto. ${ }^{19}$
\end{abstract}

Poderia suscitar dúvida do porque ainda na incerteza desse aspecto tão importante que é o controle da duração laboral. Algumas hipóteses quanto a essa perspectiva podem ser levantadas neste trabalho: própria indefinição interna do projeto ou a divulgação antecipada de informações exporia o mesmo aos profissionais que buscam auferir lucros burlando sistemas governamentais. Neste estudo prefere-se vincular a última tese, por entender que a intenção do projeto é primar pela segurança das informações.

Já com relação ao que já está instituído, ou seja, ao REP, é necessário verificar duas situações possíveis após a implementação do E- Social: Manutenção ou substituição do mesmo.

Na hipótese de o REP ser mantido para controle de jornada de trabalho será necessário uma integração com o E-Social. Poderá, contudo, ocorrer dificuldades nesta compatibilização (inconsistências, conflitos de códigos-fonte, etc), pois existem diversos sistemas disponíveis no mercado com diferentes configurações para o controle de ponto. Sugere-se então uma

\footnotetext{
${ }^{19}$ Conheça o E-Social. Portal do E-Social. Disponível em: < http://www.esocial.gov.br/>.
} 
padronização instituída pelo Ministério do Trabalho e Emprego, por exemplo, via anexo a Portaria 1510 com configurações-padrão e prazo para adaptação. Ao analisar pelo ângulo do custo aos empregadores que já adquiriram algum tipo de sistema, essa solução parece viável, mas sob a ótica de segurança das informações, é altamente questionável.

Todavia, se o REP for integralmente substituído pelo E-Social, haverá a necessidade de lançar os dados diretamente na plataforma. Evidentemente, esta seria a alternativa mais coerente se levarmos em conta o principal objetivo da plataforma E-Social: o envio de informações em tempo real. Mesmo assim, surgem questionamentos: Como fazer essa adaptação em todos os aparelhos já instalados ou ainda, seriam eles excluídos e haveria um terminal de computador em cada setor das empresas só com essa finalidade? E com relação à Internet, haveria suporte para tamanha demanda?

Essas perguntas infelizmente ainda estão sem respostas, contudo é notória a preocupação do gestor público em instituir um sistema seguro, no que tange as informações prestadas e que concomitantemente proteja o trabalhador. Esta preocupação é verificada: pela demora em se apresentar o layout final da plataforma, bem como por um estudo detalhado que verifique qual das perspectivas possíveis é mais viável e menos onerosa.

\section{CONCLUSÃO}

Em face do que foi exposto acima, se faz necessário um debate no qual sejam definidas possibilidades de solução para frear/minimizar a quantidade de lides envolvendo o controle de jornada de trabalho via REP (Registro Eletrônico de Ponto).

Analisando o que está posto, ou seja, o REP. A pretensão é justa desde sua origem, qual seja, a excelência no controle da jornada de trabalho. Entretanto, desde 2009, dada a voluntariedade na adesão, essa política aparenta ser mais facilitadora de registro de jornada do que de efetivo embate a sobrejornada.

Esse contexto atual decorre da cultura de parte da classe empresarial acobertada pela falta de imposição, a qual permite o desrespeito aos direitos do empregado. Este por muitas vezes submetido a jornada degradante por que necessita daquela remuneração para o sustento de sua família. 

ANÁLISE DOS ACÓRDÃOS PROFERIDOS PELO TRIBUNAL REGIONAL DO TRABALHO DA QUARTA REGIÃO E PERSPECTIVAS PARA A IMPLEMENTAÇÃO DO E-SOCIAL

Outrossim, verificou-se durante a pesquisa que, no período analisado (01/04/2013 a 30/09/2014) o impacto de controle de jornada pelo REP foi insatisfatório, visto que houve aumento no número de demandas em grau de recurso (de quinhentos e trinta e sete elevou-se a setecentos e setenta e dois).

Explorando conjuntamente essas duas informações, pode-se deduzir que dada a espontaneidade de participação aliada ao contingente de litígios recebidos pelo Tribunal Regional do Trabalho do Rio Grande do Sul no período analisado demonstram que o REP não atingiu o objetivo de minimizar a prática reiterada de jornadas extensas, pelo contrário, o problema só vem se agravando. Provavelmente, se a mesma política fosse obrigatória, haveria decréscimo no número de demandas.

Todavia, ao buscar respostas para a ampliação do volume de demandas - ainda que a opção seja facultativa ao Registro Eletrônico de Ponto - algumas hipóteses já podem ser levantadas, dentre elas: atuação mais efetiva do sindicato na orientação do trabalhador e maior grau de escolaridade fomentado por políticas educacionais públicas.

O sindicato tem papel fundamental no embate à jornada superior ao autorizado pela Constituição Federal, mesmo se essa não decorre de acordo coletivo. A constatação de que um empregado é submetido à jornada exaustiva revela que outros trabalhadores da mesma corporação também sofrem o abuso. Nesse sentido, é preciso incentivar a atuação do sindicato a fim de se evitar consequências desastrosas que a jornada excessiva pode gerar: a fadiga no empregado tornando-o muito mais suscetível a sofrer acidentes de trabalho. Portanto, o sindicato precisa atuar cada vez mais nesta frente em prol da qualidade de vida do trabalhador.

Quanto ao incremento instrutivo do proletariado, independentemente de posicionamento político, é notório que o acesso ao ensino da classe menos favorecida está em franca expansão. Diversas políticas públicas como o PRONATEC (Programa Nacional de Acesso ao Ensino Técnico e Emprego), PROUNI (Programa Universidade para todos) e Cotas nas Universidades Federais ampliam oportunidades. Por meio desses programas, o trabalhador munido de conhecimento vai modificar sua forma de pensar. Já dizia o filósofo René Descartes: “Penso, logo existo”. E, se o empregado começa a receber instrução passa a refletir e brevemente verificará (se até então não sabia) que é ser humano detentor de direitos.

Diversificando o debate, parte-se para a discussão sobre o controle de jornada de trabalho após a efetivação do E-Social: Como o panorama atual vai influenciar na implementação do novo sistema? A mudança será parcial ou total com relação ao REP? 

ANÁLISE DOS ACÓRDÃOS PROFERIDOS PELO TRIBUNAL REGIONAL DO TRABALHO DA QUARTA REGIÃO E PERSPECTIVAS PARA A IMPLEMENTAÇÃO DO E-SOCIAL

Conforme já dito, é prematuro fazer qualquer afirmação quanto aos procedimentos de controle de jornada que a plataforma adotará. O certo, todavia, é que a dilação do prazo para implementação só fomenta ainda mais a exploração. Para tanto, o empresário ao argumentar a necessidade de maior prazo para se adaptar, realmente pretende ficar o máximo de tempo possível sem se sujeitar ao controle rígido por parte do fisco, o qual esse sistema se propõe a efetivar. Neste sentido, novamente há necessidade de fazer referencia a Karl Marx quando este autor narra em sua obra: "Compele sempre ao trabalhador a vender sua força de trabalho para viver, e capacita sempre o capitalista a comprá-la para enriquecer-se" ${ }^{20}$.

É importante salientar também a imprescindibilidade de o gestor continuar instituindo políticas públicas e campanhas educativas voltadas ao trabalhador, pois, o maior índice de exploração por jornada humilhante está concentrado nas categorias de mais baixa escolaridade. Mão de obra esta empregada em grande medida nos chãos de fábrica e na construção civil.

Toda a reflexão que guiou o presente estudo não só pondera sobre o ambiente de trabalho e a saúde do profissional que está sendo demandando além de suas forças. Ela espelha também a preocupação com sua vivencia em sociedade. Neste sentido, é importante fazer alusão a Hannah Arendt a qual demonstra na obra A condição humana que: “o ser humano só atinge a plenitude quando participa da comunidade”. Essa participação é, sobremaneira, exercida nos momentos de lazer. Assim, à medida que o trabalhador deixa de ter o convívio social e familiar por dedicar-se demasiadamente ao labor, acaba por ter sua auto-estima minimizada, prejudicando inclusive suas relações interpessoais.

Acima de tudo é necessário uma mudança cultural daquele empregador que forja ou manipula as informações em prejuízo do trabalhador. A livre iniciativa precisa caminhar lado a lado com o respeito a dignidade humana, e isso engloba a jornada de trabalho justa.

\section{REFERÊNCIAS}

BRASIL. Constituição Federal. Brasília: Senado Federal, 1988. Disponível em:

<http://www.planalto.gov.br/ccivil_03/constituicao/constituicaocompilado.htm> Acesso em 15 nov. 2014.

${ }^{20}$ MARX, KARL, O Capital: crítica da economia política- livro 1, 15 ed. Rio de Janeiro: Berthand Brasil, 1996. p.672 
BRASIL. Decreto Lei $n^{\circ} 5452$ de $1^{\circ}$ de maio de 1943. Consolidação das Leis do Trabalho. Disponível em: <http://www.planalto.gov.br/ccivil_03/decreto-lei/del5452.htm>. Acesso em 15 nov. 2014

BRASIL. Lei n. 5.010 de 30 de maio de 1966. Disponível em:

<http://www.planalto.gov.br/ccivil_03/leis/l5010.htm> Acesso em 15 nov. 2014.

BRASIL. Lei $\mathrm{n}^{\circ} 10.803$ de 11 de dezembro de 2003. Disponível em:

<http://www.planalto.gov.br/ccivil_03/leis/2003/l10.803.htm>. Acesso em 15 nov. 2014.

BRASIL. Manual de orientação do E- Social. Disponível em:

< http://www.esocial.gov.br/doc/MOS-versao1_1minuta.pdf>. Acesso em 15 nov. 2014

BRASIL. Portal do E-Social. Disponível em:<http://www.esocial.gov.br/Conheca.aspx>. Acesso em 15 nov. 2014.

BRASIL. Portaria $n^{\circ} 1510$ de 21 de agosto de 2009. Dispõe sobre o registro eletrônico de ponto. Disponível em:

<http://portal.mte.gov.br/data/files/8A7C816A350AC8820135685CC74E1DCE/Portaria\%201510\% 202009\%20consolidada.pdf>. Acesso em 15 nov. 2014.

BRASIL. Sistema de Registro Eletrônico de Ponto. Disponível em:

<http://portal.mte.gov.br/data/files/8A7C812D32DC09BB0132DFC3C79E1478/info_empregador. pdf>. Acesso em 15 nov. 2014

BRASIL. Tribunal Regional do Trabalho $4^{\mathrm{a}}$ região. Pesquisa de Acórdãos Disponível em: <http://www.trt4.jus.br/portal/portal/trt4/consultas/jurisprudencia/acordaos> Acesso em 15 nov. 2014

BRASIL. Acórdão 0001786-73.2012.5.04.0341 RO. DESEMBARGADOR LUIZ ALBERTO DE VARGAS. Disponível em: <file:///C:/Users/USuers/Downloads/d49422140-20140710083525.pdf> . Acesso em 15 nov. 2014.

PASSARELLI, H. Governo muda cronograma pela $5^{\text {a }}$ vez e e-Social fica para 2015. O Estado de São Paulo. O Estado de São Paulo, São Paulo, 22 mai. 2014. Disponível em:

< http: / /economia.estadao.com.br/noticias/geral,governo-muda-cronograma-pela-5-vez-eesocial-fica-para-2015,185589e>. Acesso em 15 nov. 2014.

MARCONI, M. A., LAKATOS, E. M. Fundamentos de Metodologia Científica, 6 ed. São Paulo: Atlas, 2005 cap. 4, p. 83-113

MARTINS, SERGIO PINTO, Direitos Fundamentais Trabalhistas, 1 ed. São Paulo: Atlas, 2008. Direito do Trabalho, 29 ed. São Paulo: Atlas, 2013 


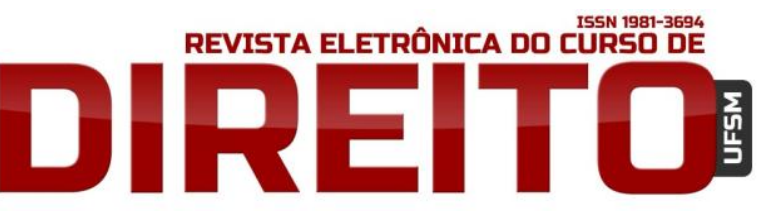

CONTROLE CONSTITUCIONAL DA JORNADA DE TRABALHO: UMA ANÁLISE DOS ACÓRDÃOS PROFERIDOS PELO TRIBUNAL REGIONAL DO TRABALHO DA QUARTA REGIÃO E PERSPECTIVAS PARA A IMPLEMENTAÇÃO DO E-SOCIAL

MARX, KARL, O Capital: crítica da economia política- livro 1, 15 ed. Rio de Janeiro: Berthand Brasil, 1996. p.605

MORAIS, JOSÉ LUIS BOLZAN DE, A subjetividade do tempo. Porto Alegre: Livraria do Advogado, 1998.

SILVA, LUIZ DE PINHO PEDREIRA DA, Principiologia do Direito do Trabalho. 2 ed. São Paulo: LTR, 1999.

TRIBUNAL REGIONAL DO TRABALHO DA QUARTA REGIÃO. Calendário 2013. Disponível em: <file:///C:/Users/USuers/Downloads/C2013_com_RA13.2013.pdf>. Acesso em 15 nov. 2014.

TRIBUNAL REGIONAL DO TRABALHO DA QUARTA REGIÃO. Calendário 2013. Disponível em: <file:///C:/Users/USuers/Downloads/C2014.pdf> . Acesso em 15 nov. 2014.

TRIBUNAL REGIONAL DO TRABALHO DA QUARTA REGIÃO. Portaria n. 1.423 de 18 de março de 2014. Disponível em <file:///C:/Users/USuers/Downloads/1423.pdf> Acesso em 15 nov. 2014.

UFSM. MDT 2012. Disponível em:

<http://coral.ufsm.br/prpgp/images/fomularios-diversos/mdt-2012.pdf>. Acesso em 15 nov. 2014.

Recebido em: 06/08/14 / Revisado em: 03/11/2014 Aprovado em: 19/11/2014 